\title{
EL PODER LOCAL EN LA CASTULA DE LA RESTAURACIÓN. FUENTES Y MËTODO PARA SU ESTUDIO
}

\author{
por \\ PEDRO CARASA SOTO \\ Universidad de Valladolid.
}

RESUMEN: El artículo expone los presupuestos metodológicos y las bipótesis de trabajo de un proyecto de investigación sobre el poder local en Castilla. Explica primero las razones externas e internas que justifican la tendencia bacia el microanálisis y la perspectiva local del poder en la bitoriografia y expone en segundo lugar los rasgos más salientes de este poder local en el caso castellano. En esta segunda parte se define dicho poder como una realidad construida desde abajo, multiforme, fragmentada, enraizada en 10 más primario de la sociedad, territorializada, modulada por el entorno, $y$ en interacción con la respuesta social.

PalAbras Clave: Poder local. Restauración. Ayuntamientos, Castilla.

\begin{abstract}
This article sets out the metbodological foundation and working bypotheses of a research projet on local power in Castile. Firstly it explains external and in. ternal reasons that justify the tendency towards microanalysis, and secondly it shows the most significant cbaracteristics of this local poiver in the case of Castile. In this second part, this local power is defined as a reality built from below, multiform, fragmented, deeply-rooted in the most basic elements of society, territorialized, and changed by the environment and in interaction with the social response.
\end{abstract}

KEY WORDS: Local power. Restabration. Municipal governments. Castile.

Hiparaia, LIX/t, núm. 201 (1999) 9-36 


\section{INTRODUCCIÓN}

Es obligado, como paso previo, hacer referencia al proyecto de investigación que ha motivado estas reflexiones metodológicas ${ }^{1}$, titulado Elpoder local en Castilla. Alcaldes y gobierno municipal durante la Restauración, y aprobado por la DGICYT con el $n^{\circ}$. PB $94 / 1120$. El planteamiento inicial de la investigación se dirigía hacia la prosopografia de alcaldes y su contraste con el gobierno municipal que desarrollaban en las ciudades castellanas, pero la reflexión metodológica que tratamos de tecoger en este conjunto monográfico de artículos nos ha aconsejado derivar la investigación hacia ámbitos y aspectos más microanalíticos del poder local. Buena culpa de esta nueva orientación tuvo el Taller sobre El poder local en Castilla. Fuentes y métodos para su análisis, celebrado en la Facultad de Letras de Valladolid, en febreto de 1996, por los miembros del equipo en abierto e intenso debate con algunos de los mejores especialistas que actualmente trabajan este aspecto en la historiografía española. Pudimos constrastar nuestras propuestas con Manuel Martí ${ }^{2}$, de la Universidad de Valencia, con Eliseu Toscas ${ }^{3}$, historiador barcelonés estrechamente vinculado a la historiografía italiana que desarrolla estos temas, Salvador Cruz Artacho ${ }^{4}$, especialista de la Universidad de Jaén que analiza el poder local en Andalucía y Francisco de los Cobos, que se ocupa en semejante tema desde la Universidad de Granada; también Santiago Díez Cano de la Universidad de Salamanca, miembro del equipo, ofreció a nuestra consideración un interesante estado de la cuestión sobre el particular. Se trata de visiones complementarias y entiquecedoras del mismo problema, de forma que abarcamos casi la totalidad de las

1 La investigación en curso está siendo desarrollada, bajo la dirección de Pedro Carasa como investigador principal, por el siguiente equipo: Doctora Margarita Caballero, profesora del Colegio Universitario de Soria perteneciente a la Universidad de Valladolid; Licenciada Pilar Calvo, profesora de la Facultad de Filosofia y Letras asimismo de la Universidad de Valladolid; Doctor Santiago Diez Cano, profesor de la Facultad de Geografia e Historia de la Universidad de Salamanca; Doctor Antonio Fernández Sancha, profesor de la Facultad de Educación y Humanidades de la Universidad de Burgos; Licenciada Sonsoles Gómez Cabornero, profesora de la Escuela Universitaria de Trabajo Social y Relaciones Labotales de Palencia perteneciente a la Universidad de Valladolid; Doctor Vidal Pelaz, profesor de la Facultad de Filosofia y Letras de la Universidad de Valladolid; y Doctor Rafael Sertano, profesor de la Facultad de Educación de la Universidad de Valladolid, así como los becarios colaboradores Enrique Berzal, becario del programa de Formación del Personal Investigador y Ptofesorado del Ministerio de Educación y Cultura; y Juan Antonio Cano García, colaborador honorífico del Departamento de Historia Contempotánea de la Universidad de Valladolid.

2 M. MarTh, «Elogi de la discontinuitat. El poder politico local entre els segeles XIX y XX", en Actes del II Congres International d'Historia Local de Catalanya. Formes y relacions del poder local a l'época contemporanian, Barcelona. L'Avenç, 1995.

3 E. ToscAs, L'Estat y als poders locals a la Catalunya del segle XIX. Barcelona. Abadia de Montserrat, 1997.

4 S. CRUz ARTACHO, Cacigues y campesinor. Poder politico, modernizacion agraria y conflictividad mral en Granada, 1890-1923. Córdoba, 1994.

Hipania, LJX/1, núm. 201 (1999) 9-36 
posiciones metodológicas frente al poder, desde la más inclinada a la valoración del conflicto en los ámbitos meridionales, hasta la comprensión más integral del poder como una realidad muy fragmentada y vinculada a los sujetos y las comunidades que lo soportan, tal como se contempla desde las zonas levantina y catalana.

De acuetdo con las pautas metodológicas que dedujimos de este taller y a raiz del debate interno del equipo, hemos optado por centrar el trabajo de investigación en un nivel mucho más local, de distrito o de ciudad, y posponer la idea de un estudio masivo regional. Nos hemos planteado concretar los espacios de análisis a algunos ámbitos de la región muy específicos que reúnen interesantes características especiales y buenas condiciones de fuentes. Nos centraremos, en primer lugar, en la ciudad de Burgos, como un destacado escenario urbano dotado de excelentes archivos municipal, provincial, diocesano, y marco de los movimientos de una élite de gran interés, donde el localismo arraigó con sus dos aspectos bien definidos: una identidad burgalesista muy acusada y una marcada contraposición al resto castellano, especialmente vallisoletano. El segundo espacio escogido ha sido el medio rural que se inscribe entre Medina de Rioseco y Villalón, con atractivos recursos documentales, con la peculiaridad de ser un medio agrario de Tierra de Campos estrechamente vinculado a la ciudad de Valladolid pero con la posibilidad de resultar un modelo de poder y elite bastante extensible a numerosos ámbitos agrarios castellanos. En tercer lugat, se ha preferido el escenario mirobrigense que presenta unos rasgos fronterizos, semilatifundistas, a medio camino entre lo urbano y lo rural, de fuerte implantación del sindicalismo católico y de la jerarquia episcopal, con importantes familias liberales muy arraigadas y cuyo centro, Ciudad Rodrigo, dispone de documentación suficiente y constituye un ejemplo de lo que podríamos denominar la "Extremadura castellana». En cuarto término será la ciudad de Soria el escenario de un ejercicio de poder local muy interesante por sus especiales relaciones periféricas con el resto de la región y por las peculiaridades que ofrecen algunos de sus más eminentes personajes. Un quinto escenario se situará en la ciudad de Palencia, para la que afortunadamente contamos con abundante documentación e importantes análisis de sus relaciones de poder que nos permitirán realizar un microanálisis de protagonistas concretos. Estos ámbitos permiten analizar diversas situaciones castellanas susceptibles de generar modelos relativamente aplicables a otros medios, dan la posibilidad de hacer historia comparada, y son abarcables para practicar una microhistoria del poder.

El objetivo es realizar una disección microscópica del poder concretado en unos protagonistas determinados que se mueven en cada uno de esos espacios, abarcando la mayor cantidad posible de sus dimensiones, políticas, económicas, sociales, religiosas, etc., juntamente con sus implicaciones institucionales, municipales, provinciales, sus contactos y redes familiares, patrimoniales, profesionales, etc. Las reflexiones que siguen a continuación pretenden servir de pautas metodológicas para este análisis, han sido concebidas a partir de la ex- 
periencia previa de investigación del poder parlamentario en Castilla, modeladas en el debate citado y enriquecidas por las colaboraciones de los especialistas invitados.

Además de estas circunstancias externas mencionadas, la elección del tema del poder local ha venido dictada, casi de forma ineludible, por el anterior proyecto de investigación que acabamos de editar en dos volúmenes sobre Elites castellanas de la Restauración. Todos los indicadores y resultados de la investigación nos forzaban irremediablemente a centrat el objetivo investigador desde la prosopografia general al microanálisis, a perseguir las huellas del poder reduciéndolo desde el ámbito parlamentario nacional al espacio provincial y de distrito, a entender mejor la naturaleza del poder fragmentado desde las esferas de las instituciones, la sociedad y la política local, en definitiva, a derivar desde el poder político general al poder local.

El objetivo, pues, se ha de centrar en la búsqueda de las taíces y características del poder en los círculos más reducidos y en los aspectos más concretos y vinculados a la persona, la familia, el territorio, la ciudad, buscando los componentes más primatios del poder. Con este objetivo haremos aquí algunas teflexiones ${ }^{5}$ sobre la naturaleza del poder, sobre los elementos más inmediatos que lo integran y sobre las aportaciones que han realizado las diferentes interpretaciones historiográficas, especialmente las más recientes. Sirvan estas líneas para exponer a la comunidad científica interesada en temas afines nuestros presupuestos metodológicos y someterlos a la crítica y al contraste de otros investigadores embarcados en proyectos semejantes.

\section{POR QUÉ EL ANÁLISIS DEL PODER SE ENRIQUECE DESDE SU PERSPECTIVA LOCAL}

\subsection{Razones historiográficas externas yue abonan la perspectiva local del poder}

Son numerosas las razones externas que inducen a cambiar metodológicamente del macro al microanálisis del poder. Varios autores, entre ellos los que colaboran en este número monográfico, particularmente E.Toscas, señalan la interacción entre una serie de mutaciones sociales y políticas, la proliferación de movimientos regionalistas o étnicos en Estados industrializados, la crisis del Estado-nación por presiones internas y externas, el descrédito sin precedentes de la "gran políticas, a menudo alejada de la vida cotidiana, la renovación epistemológica operada en historia política, la mutua influencia existente entre fe-

5 Buena parte del contenido de estas páginas introductorias son el fruto de mi participación en el Seminario sobre Historia Local organizado por los Cursos d'Estiu de la Universitat de Girona en Julio de 1997, donde expuse parte de estos contenidos bajo el título «Poder local y élites en Castillas.

Hiptania, LlX/1, núm. 201 (1999) 9-36 
nómenos sociales y pautas historiogxáficas, o la mayor atención hacia la dimensión territorial de los procesos históricos, entre otras.

El discurso historiográfico se halla en estos momentos revisando los anteriores modelos interpretativos dualistas, y sin perder el legado interpretativo que nos han dejado, aparecen nuevas teleologías no necesariamente dialécticas que van más allá de las viejas coordenadas que se habían atascado en los dilemas atraso/progreso, feudalismo/capitalismo, absolutismo/ liberalismo, sociedad rural/ mundo urbano, o burguesía/proletariado; estas grandes macroconcepciones, con ser ricas en explicaciones e interpretaciones generales, estaban sin embargo dificultando que se complementaran con los fenómenos primarios y más elementales relativos al sujeto, al tiempo y al espacio protagonistas de la historia. Hoy parece entiquecerse esa visión anterior con una concepción pluralista, multilineal y con una multiplicidad de modelos 6 .

Otras circunstancias externas a la historia misma están empujando a la historiografía a reducir la escala de observación, en particular desde el marco nacional-estatal a los ámbitos regionales y locales. La nueva historia política ha de convertir la vieja historia (evenemencial) en historia social del poder y de los grupos dirigentes, de forma que se consiga reunir en una unidad dialéctica e integral economía, sociedad y política, cruzar sus datos con la historia social, económica y cultural, dotar de contenido social el poder político y atraparlo en todas sus manifestaciones (políticas, sociales, económicas, ideológicas). Las anteriores visiones estatalistas y generales no han conseguido contemplar al Estado en diálogo e interacción con los otros protagonistas del poder, pero el Estado, como aparato de dominio, ha necesitado siempre de la mediatización local de grupos sociales, a los que ha transmitido su influencia y al propio tiempo de los que ha recibido un fuerte influjo, porque el poder es fundamentalmente interacción. Los exclusivos niveles político-institucionales centrales no habian permitido ver en toda su complejidad las articulaciones del poder politico, las maneras como éste se relaciona con la sociedad civil, las diferentes vías por las cuales los Estados modernos extienden a la periferia su poder. La integración entre ambos elementos muchas veces se ha producido de manera forzosa, ha sido de tipo coactivo, pero también se han dado integraciones simbólicas a base de fidelidades tradicionales o nuevas, con complejos sistemas de transacción con poderes intermedios.

También ciertas corrientes historiográficas internacionales que daban por únicos los viejos modelos septentrionales habían producido distorsiones entrc nosotros; como señala Toscas en el artículo de este número monográfico, una concepción unilineal y absolutamente progresista del desartollo histórico de acuerdo con el modelo inglés había presentado a países como España o Italia como una suerte de Inglaterras poco evolucionadas. Y las historiografias meridionales han reaccionado insistiendo en los cauces autóctonos de evolución,

6 Cft. la reciente traducción de la obra de P. MACRY, La Sociedad Contemporánea, Barcelona, 1997, particularmente páginas $48-62$.

Hispanis, LIX/1, núm 201 (1999) 9-36 
distinta sin duda a la septentrional, pero en todo caso progresiva y transformadora. En esta dirección es particularmente interesante la consideración del poder que presenta Toscas, que está construida en un fecundo diálogo con la historiografia italiana?. En cualquier caso, comienzan a normalizarse entre nosotros los estudios comparativos, particularmente con Italia, Francia y Portugal, relativos al poder y la participación políticas.

\subsection{Razones histớricas internas que indican el origen local del poder}

Hay quien sostiene que en el caso español y particularmente en el castellano, el ritmo lento del cambio general pudo estimular el cambio local. El franco retraso de las posibilidades transformadoras en el nivel institucional y general acentuaron e incentivaron el hecho de que las iniciativas de cambio fueran principalmente de tipo local. Parece que se impone, en relación con esa observación anterior, la constatación de que la construcción del poder se inicia desde abajo. Los espacios periféricos del sistema político han sido minusvalorados en su capacidad de construir poder, de acuerdo con la idea extendida ${ }^{\text {" de que el }}$ sistema funcionaba de arriba abajo, sin embargo esos espacios inferiores y el proceso ascendente cobran ahora especial importancia. La espina dorsal del sistema se conformó desde abajo, desde las esferas locales del poder, donde los espacios rurales imponían sus universos conceptuales y sus pautas de comportamiento. En el artículo que inserta en este número S. Cruz Artacho recuerda que comienza a dibujarse una linea interpretativa en la que, "sin menospreciar la existencia de flujos descendentes, el reticulado clientelar ofrece una marcada proyección ascendente».

7 E. TosCAS, «Conflitti e discorsi di legittirazione in una comunitá locale catalana nellOttocenton, Quaderni Storici, 1996 (en prensa); A. IASSAFR, (Le ragioni di una propostas, en A. MASsAFrA (a cura di), I/Mezzogiono preunitario. Economia, societá e istitutioni, Bari, 1988; R. RoMANELL, «La formación de los Estados nacionales en la Europa del siglo XIX. Notas sobre un proceso socialm, en P. Rutz TORres (ed.), Europa en su bistoria, Valencia, 1993; R. ROMANELL, «La nazionalizzazione della periferia. Casi e prospettive di studion, Meridiana, $\mathrm{n}^{\circ}, 4,1988$, pp. 13-24, introducción al número monográfico de esta revista dedicado al tema «Poteri localib; G. GRIBAUDI, A Eboli. Il mondo meridionale in cent'anni di trasformazioni, Venecia, 1990; R. ROMANEILI, Il comando impossibile. Stato e societá nell' Italia liberale, Bolonia, 1988; la revista Quaderni Storici, $n^{\circ} .63$ (1986) (editada por S. Lombaroins, O. RAGgio, A. Torre) está dedicada a "Conflitti locali e idiomi politicis; el nº. 77 (1991) (editado por A.M. BANT e M. MERIGGI) se titula «Elites e associazioni nell'Italia dell'Ottocento»; el número de 1996 editado por G. Gribaudi estudia «La legittimazione politican; G. CIvILE, I/ comune rustico. Storia sociale di un paese del Mezrogiorno nell'800, Bolonia, 1990.

${ }^{8}$ S. Forner (Coord.), Democracia, elecciones y Modernizacion en Europa. Siglos XIX y XX. Madrid, 1997.

9 Era la clásica descripción de J.M. Jover ZAMOrA, «La época de la Restauración: panorama políticosocial, 1875-1902», en Manuel Tữón DE Lara (Dir), Historia de España. Tomo VII1. Revolución burguesa, oligarquia y constitucionalismo, 1834-1923. Barcelona, 271-394.

1Hipania, LIX/1, núr. 201 (1999) 9-36 
Es preciso conceder una mayor importancia a los elementos llamados formalmente débiles. Incluso Artacho lo hace, citando a John Davis ${ }^{10}$ dice que el protagonismo de estos elementos debería reforzarse considerando la justificación de la clientela por parte de los clientes, ya que éstos pueden llegar a controlar a veces la prepotencia del superior sencillamente reconociéndolo como tal; de esta manera acceden a los recursos y el patronazgo podía llegar a convertirse, de hecho, en un mecanismo por el que «los débiles controlan la autocracia de los magnates locales». El resultado de esta nueva perspectiva es el fortalecimiento de las esferas locales del poder en la explicación del sistema político considerado en su conjunto, aunque algunos de estos últimos aspectos mencionados no tengan la misma importancia ni sean siempre demostrables.

La desarticulación regional ha contribuido también en algunos espacios a que aflore con fuerza el poder local. En nuestro caso castellano, la no integración de un espacio regional, como ya hemos avanzado en otras publicaciones, es otra característica de esta peculiar vinculación territorial del poder local. Todo lo débil que es el vínculo con el resto de las provincias castellanas así de fuerte es el lazo con el territorio más inmediato; es más, puede decirse que precisamente por ser débil aquél se hace más fuerte éste. El localismo ha sido históricamente el gran argumento de legitimación del poder. Este localismo constituyó sobre todo un intrumento de sanción en los ámbitos castellanos frente a Madrid. Incluso quienes intentaban romper el turno de los partidos dinásticos, se apoyaron en el localismo frente a unos políticos que, enredados en sus luchas de facciones, supuestamente no defenderian bien los intereses de su provincia o distrito. Es cierto que el proteccionismo, excelente exponente de los influjos del poder local, produjo cierto nivel de unidad regional, siquiera emocional, y actuó de movilizador de las Diputaciones y de los parlamentarios consiguiendo elaborar un smensaje de Castillay y definir ciertos consensos en tomo a la región que casi llegaron a considerarse sagrados. Pero a pesar de todo, en Castilla primó de forma contundente lo provincial sobre lo regional y lo local sobre lo provincial; justamente por carecer de una implantación fuerte de regionalismo creció desmesuradamente el nivel local de aspiraciones y poder.

\section{REFLEXIONES SOBRE IA NATURALEZA DEL, PODER LOCAI. Y SU INVESTIGACION}

Las siguientes líneas tratan de recoger los perfiles que dibujan el poder local, según la experiencia de nuestra investigación, y constituyen una especie de hipótesis de trabajo que está tratando de ser verificada en nuestro ámbito. Se trata de una serie de rasgos del poder local que estamos aplicando a la realidad histórica castellana de la Restauración, no sólo en su concepción teórica y comparativa, sino también en su aplicación práctica.

10 Jolin Davis, Antropologia delle societá mediterranee. Un'analisi comparata. Torino, Rosenbetg \& Sieller, 1980, 135-137.

Hispania, LIX/1, núm. 201 (1999) 9-36 


\section{1. ¿Historia local o microhistoria del poder?}

No aspiramos a una historia local como meta, el análisis de lo local en sí no representa para nosotros el objeto histórico principal, sino que nos servimos de la historia local como mero escenario, no nos interesa tanto el territorio como el problema del poder, y cuando nos fijamos en el territorio es como escenario y elemento de poder. Analizamos este poder en el espacio concreto que mejor conocemos y cuyas fuentes nos son accesibles, queremos, pues, hacer microhistoria del poder y para ello hemos elegido el ámbito castellano cuyas características y entorno nos son más próximas intelectualmente. Pero en ningún momento pretendemos una historia local de los ayuntamientos o de los alcaldes. Queremos tealizar un análisis social de la política desde una perspectiva de media duración. Los objetivos de nuestras investigaciones, pues, no van encaminados a conocer estrictamente lo más local del poder, sino la dimensión y naturaleza general del poder en un escenario local, tratamos de insertatlo en un modelo explicativo más amplio, referido sobre todo a un análisis social de la política desde una perspectiva de tiempo largo pero de corto espacio. Aplicado a nuestro caso, podemos concluir que las cuestiones referidas al poder local son sólo una dimensión de nuestro análisis social del poder en la Restauración, pero pretendemos que sean más microhistóricas que localistas.

Este planteamiento conlleva en la base un cambio en la visión del poder y del Estado. Lo que, obviamente, implica abandonar numerosas viejas concepciones estatalistas del poder central y atisbar cómo se descubren relaciones inéditas entre lo estatal y lo local y cómo la mayor parte de las veces la iniciativa parte de abajo, como hemos adelantado ya, el protagonismo está en lo concreto y desde atriba frecuentemente sólo se tiene margen pata teaccionar y adaptarse a estas exigencias locales. La propia autoridad estatal, en tanto que aparato de dominio, necesita de la mediatización constante de grupos sociales específicos locales, los cuales se hacen representantes y depositarios de aquélla a cambio de recibir prestigio y ottos elementos de dominio sobre las poblaciones. Este nuevo enfoque del poder y del Estado comporta logros relevantes, como son la recuperación de una nueva perspectiva política, la importancia del análisis cronológico a medio plazo y una insistencia destacable en la interpretación social de la política. Otta conquista implícita en este punto de vista es la nueva manera de entender la hegemonía con implicaciones mixtas de coerción y consenso ${ }^{11}$, como explicarán más adelante $\mathrm{M}$. Martí o el mismo Salvador Cruz.

\subsection{El poder desde abajo: la historia social del poder}

En otro lugat hemos escrito que el poder sigue un itinerario ascendente en su construcción y descendente en su diseño. $Y$ hoy creemos que resulta más

\footnotetext{
11 Por las influencias de autores como J. Scort, J. HABERMAS, J. KOCKA, A. LFHTKE O H.
} MEDICK.

Hitpathia, LIX/1, núm. 201 (1999) 9-36 
operativo para el análisis histórico seguir el itinerario ascendente de su construcción y no el descendente de su diseño, como se hacía antes. Habitualmente se había seguido el camino de las hipótesis generales, pero estábamos a falta de biografias y diccionarios biográficos que en otras historiografias occidentales ya se habían mostrado como necesarios y socorridos. Era hora de insistir entre nosotros en el camino que va de lo particular a lo general, en la prosopografia que parte de biografías y microanálisis de personas, instituciones, distritos y espacios reducidos. Conocemos más o menos bien, escribia no hace mucho J. Suau ${ }^{12}$, quién manda, pero nos falta responder a sucesivas preguntas sobre cómo manda, para qué manda, qué manda y a quién manda. A responder todos estos interrogantes se accede mejor desde abajo.

Se impone así el método inductivo que parte de las redes primarias hacia la comprensión integral del poder. Tras las meritorias interpretaciones generalistas, hemos de reconocer que como explicaciones históricas se han mostrado incompletas y parciales, puesto que aplicadas a los casos concretos no parecen capaces de agotar e interpretar exhaustivamente la realidad local. Ese planteamiento impedía que pudiéramos acercarnos a descubrit la polivalente realidad de un poder compuesto y conformado por unas redes multifacéticas, por abundantes factores antes olvidados que hoy parecen decisivos. Se está imponiendo esta tendencia de considerar la construcción del poder en un proceso ascendente, como acaba de mostrar para una provincia castellana una tesis doctoral reciente ${ }^{13}$ que ha basado en este tipo de estructura casi toda la naturaleza del podet, haciéndolo consistir básicamente en un conjunto de relaciones primarias e informales que arrancan casi en exclusiva de la familia, la vecindad $\mathrm{y}$ las vinculaciones con el espacio.

\subsection{El poder multiforme: superación de las explicaciones univocas}

En el pasado ha dominado en exceso una percepción del fenómeno muy dualista y se ha marginado todo aquello que partiendo de abajo no se ajustara a las grandes coordenadas dialécticas y de conflicto. Algunas de estas redes o factores de poder fueron minusvaloradas en el pasado como supetficiales, supraestructurales se decía, y poco importantes en la construcción del poder, pero ahora se nos presentan tan decisivas y relevantes como los viejos parámetros de la propiedad, de la organización patronal, del control de los medios de producción, sin necesidad de excluir ni de contraponer maniqueamente ninguno. Nos habían proporcionado una percepción del fenómeno muy diádica y basada, o bien en la interpretación económica, o bien política, pero ello se pro-

12 J. Sunu, «Qui mana? Com? Per qué? Estudi de les relacions de poder en les col-lectivitats ruralso, en L'Aveng, 160 (1992).

$13 \mathrm{~J}$. VIL1,A ARRANZ, Las élites y el poder en la crisis del primer terio de siglo. Relaciones sociales $y$ actores colectivos en Palencia (1914-1936). Universidad de Valladolid, Octubre de 1997.

Hitpania, LIX/I, num. 201 (1999) 9-36 
ducía siempre en detrimento del estudio de las relaciones del poder con la sociedad.

El factor económico sigue siendo reconocido desde entonces como muy importante, pero no determinante. Es incuestionable, a pesar de todas las polémicas, que hay una decisiva componente económica en el poder político, pero no es la única, ni agota lo más substancial de la naturaleza de esa relación de poder. Las élites políticas, en su dimensión histórica real, como hemos constatado en nuestro estudio sobre Castilla, no ejercen un poder de naturaleza básica y principalmente política, contienen en sí elementos económicos importantes y más principales aún componentes familiares, sociales, culturales, etc. que son más definitotios que el propiamente político. Lo definitivo es articular e integrar todos esos aspectos sin exclusivismos, poder político y poder económico se necesitan, se relacionan, se rechazan, se apoyan, a veces aparentemente se identifican, pero no constituyen una misma realidad.

\subsection{El poder fragmentado: multiplicidad de âmbitos de poder}

Se ha producido una diversificación de las fuentes del poder en la mente de los historiadores a la hora de investigar su origen y su naturaleza. La concepción del poder ha de ser necesariamente deudora de lo que entendamos por sus fuentes de construcción y alimentación, en función de estos orígenes han de configurarse las distintas facetas o dimensiones del mismo, y de aquí es de donde arranca una de sus principales características: su fragmentación. No existe un poder perpetuo, oligárquico, monolítico y no contestado, la realidad que habitualmente encuentra el historiador es más poliédrica. La primera necesidad parece indicarnos que hay que entender el poder en un sentido poliforme, no reducido -como hace algunos años-a la mera consideración del Estado o las instituciones políticas en su relación con los ciudadanos, sino comprendido en todas sus dimensiones y relaciones, sean formales o informales, primarias o secundarias, se refieran a la política, la sociedad, la ideológica o el simbolismo. Como señala Angels Solá ${ }^{14}$, este cambio en la consideración de lo que es el poder ha puesto en primer plano formulaciones más ricas y complejas. De esta forma se ha impuesto una atención preferente no sólo al origen variado del poder, sino a las distintas facetas o dimensiones del mismo, es decir, a su fragmentación.

Esta concepción poliédrica del poder nos ofrece una realidad asimétrica, un fenómeno autónomo, político y sobre todo social, dentro de un proceso de construcción del Estado y condicionado por su peculiar relación con las comunidades locales. Un poder complejo, más bien una serie de poderes locales combinados, que abarcan aspectos legales, de propiedad, de partidos, que se

14 A. SolÁ, «Poder político y grupos de presión», en P. CARASA, Edit., Elites. Prosopografía Contemporánea. Valladolid. 1994, 25-40.

Hippanie, LIX/1, nưm 201 (1999) 9-36 
vincula al espacio estrechamente, que marca fuertemente los rasgos de proximidad, de redes personales, de nexos familiares, de interrelación campo-ciudad.

Hay que avanzar más allá de las interpretaciones del poder tradicionales, monolíticas y unidireccionales, pero nunca abjurar ni renunciar a las viejas conquistas; no entramos en contradicción con la historiografía clásica, entramos en diálogo y enriquecimiento con respecto a ella. ¿Qué consecuencias podemos sacar de esta manera relativamente diferente de analizar el poder? En primer lugar, la que nos obliga a ampliar los planteamientos en exceso simplistas de presentar las relaciones de poder, es decir, nos empuja a enriquecer las tradicionales interpretaciones del poder económico en bloque o del poder político tepartido entre amigos con otras consideraciones que lo relacionen con la sociedad donde nace y se ejerce. Algunos autores han planteado la posible complementariedad de esas visiones tradicionales y han sostenido su compatibilidad con las tendencias actuales, tratando de resumirlo últimamente en la política del pacto de tipo armonizador y anticonflictivo ${ }^{15}$. Hoy, sin embargo, dados los avances producidos en la investigación en los últimos años, cabe la posibilidad de plantear nuevos enfoques que superan esos esquemas explicativos, se sitúan en otta onda y aportan nuevos caminos con mayor capacidad explicativa ${ }^{16}$. Pero en cualquier caso todos insisten en la fragmentación del poder como un presupuesto nuevo inexcusable.

\subsection{El poder enraizado: desde las dimensiones primarias de la sociedad}

El territorio es una de esas primarias dimensiones con que se relaciona el poder, tal como reiteradamente se nos ha aparecido en el caso castellano analizado. Podríamos decir que una de las líneas que con más fuetza nos ha trazado la documentación ha consistido en ligar a los elementos del poder y de la élite que lo detenta con los círculos más primarios e inmediatos de su entorno, con lo más directo y trabado de la persona protagonista. Es extraordinaria la nitidez y la fuerza con que se muestra, por ejemplo, el territorio, por no decir la tierra ${ }^{17}$. La procedencia, el origen familiar, el distrito, el localismo, la provincia, las instituciones de poder local son realidades primordiales a la hora de explicar el origen, los protagonistas y la función de las élites y su poder.

15 M. Sierra, La politica del pacto. El sistema de la Restauración a través del Partido Conservador Sevillano (1874-1923). Sevilla, 1966.

16 Una exposición de estas nuevas líneas de interpretación, particularmente de la élite de poder como intermediatio entre el poder central y la comunidad local, como mercaderes o prestamistas de un capital político a cambio de unos intereses casi usuratios en forma de beneficios privados, puede consultarse en la obta P. CArASA, Dir., Elites Castellanas de la Restauración. I. Una aproximación al poder politico en Castilla, Valladolid, 1997, 10-96.

17 P. CARASA, «Poder de las élites y agricultura en Castilla. Tierra y territorio en la construcción del poder político", en El poder de las élites en la sociedad mediterrínea. Jornadas preparativas de la Sección 38 del 40 Congreso de la Asociación Internacional de Historia Económica, celebradas en Noviembre de 1997.

Hi.pattia, LIX/1, núm. 201 (1999) 9-36 
La familia compone otro círculo, semejante al territorio, inmediato al titular del poder, que resulta imprescindible para su comprensión. Es un elemento básico en la configuración vertical y horizontal de la elite porque con demasiada frecuencia se halla en los orígenes del poder, con mayor insistencia se muestra un cauce definitivo para perpetuarlo y reproducirlo, y en numerosas ocasiones constituye un elemento de legitimación del poder. Nunca legaremos a exagerar el papel de la familia en las élites castellanas de poder local, tal como hemos puesto de manifiesto en el anterior proyecto de investigación. Aquí radica otra clave fundamental de explicación de su estructura y comportamiento. Ha sido frecuente caracterizar a estas élites de "amigos políticos», en frase afortunada de la época y generalizada por algún especialista, pero creo que podría ser más expresiva y verosímil aún la de "parientes políticos» o "familias políticas», en el doble sentido de parentesco ideológico y biológico, puesto que son dos de los elementos articuladores más importantes del poder. El término familia de este modo nos sirve no sólo con valor analógico para explicar cómo se construyen vinculaciones y dependencias ideológicas que dan lugar a facciones compuestas por verdaderos parentescos políticos, sino para expresar ya con su significación directa el destacado papel de la sangre en la conformación del poder político. Pero además de la función vertical de la familia para construir generaciones que patrimonializan el poder, hay otra tan o más importante de tipo horizontal que va creando redes de interconexión de sagas, atendiendo a unas estudiadas estrategias familiares que emparentan a lo más granado de la política con los negocios, la propiedad, los altos cargos en el ejecutivo, o los políticos locales. Era tan importante para un jerarca central echar raices locales, como para un cacique local conectar con la cúpula.

La vecindad es otro elemento que configura el poder. Uno de los más sólidos integrantes constructores del poder en Castilla ha sido un estricto localismo, una realidad que, además de la relación con el territorio ya señalada, introduce otro carácter primario del poder que es la vecindad. Se trata de la percepción del hecho de formar parte de una comunidad concreta que se aprecia como primer y fundamental sujeto de las relaciones con el Estado, con las esferas intermedias de la provincia y particularmente con las restantes comunidades circundantes en oposición a las cuales frecuentemente se concibe a sí misma. Esta vecindad es la que pone nombre al localismo, de manera tal que se transforma en burgalesismo, leonesismo, sorianismo, y en definitiva es la que acaba definiendo en primera instancia las legitimaciones del poder.

Las instituciones locales siguen en orden de importancia en esta secuencia de elementos integrantes del poder vinculados a lo más primario. En estudios catalanes y en el nuestro castellano se confirma la desigual influencia de las Diputaciones y los Ayuntamientos en este sentido. Se ha demostrado, por ejemplo, que el desempeño de cargos en la Diputación fue un recusso más frecuente que ejercerlos en el Ayuntamiento de cara a obtener el acta de diputado. Esperamos en nuestra investigación actual aclatar algunas de las razones que pueden latir bajo esta diferente influencia municipal o provincial que representan dos esferas diversas y a veces contrapuestas de localismo.

La profesión y la actividad continúan definiendo más elementos constructores del poder relacionados con el lugar donde se ejerce. El significado de la

Hispanis, LIX/1, núm 201 (1999) 9-36 
profesión de los detentadores del poder político ha sido subrayado en nuestra investigación anterior con unos influjos poderosos en varias direcciones. $\mathrm{La}$ primera se produce en sentido vertical hacia abajo, a la hora de propiciat una apretada relación y la creación de vínculos clientelares con el resto de la sociedad inferior. La segunda se dibuja en sentido horizontal de red, por medio de un habitual intercambio de actividades y profesiones que estrechaba la capacidad de entablar relaciones de negocios, de dedicación, de participación en instituciones y cargos, con el resto de los miembros de las élites. En tercer lugar, la profesión y actividad genera relaciones verticales hacia arriba, permitiendo una fluida comunicación con las fuentes superiores del poder, con las instituciones y personas que lo detentan. El decisivo papel de la actividad y la profesión se ha manifestado también en el entrelazado de las élites. Además de reflejar los altos estratos de la sociedad castellana, la sorprendente combinación de las profesiones es una expresión fidedigna de la cohesión de las élites dentro del estrecho mundo local, del intercambio de intereses muy inmediatos y próximos entre ellas.

Grandes familias y sagas son las encargadas de localizar y personalizar el poder. Nos referimos aquí a las dos dimensiones de la familia antes mencionadas en relación con el poder local. En primer lugar debemos señalar que son las relaciones familiares los conductos preferentes para construir y ejercer el poder, ya nos hemos referido a la tesis doctotal de Juan Villa que acaba de ponerlo de manifiesto para el caso palentino. Pero hay además otra dirección en la que actúa la familia y es en la concentración de este poder en sagas y canales de perpetuación y oligarquización del poder, tal como hemos puesto de relieve en nuestra aproximación al poder político en Castilla, donde destacan grandes concentraciones familiares del poder. Obviamente, no son todas de la misma talla, no se repiten en todas las provincias cabezas del primer nivel como Gamazo, Alba, Dato o Silvela, que son capaces de articular familias políticas supraprovinciales, pero si existen en todas familias de élites de un relieve secundario, pero con una gran fuerza constructora y articuladora de poder.

\subsection{El poder territorializado: los básicos soportes del poder son espaciales}

Ayuntamientos y secretarias son los espacios en que ahora pretendemos fijarnos prioritariamente. Es aún notable la precariedad de la historiografía municipal entre nosotros, falta por hacer una buena historia de los Ayuntamientos. Se han iniciado trabajos para las Diputaciones, sin duda por hallarse estás más próximas al comportamiento caciquil general y por la visión desde artiba predominante, pero hay que insistir en crear modelos para abordar estas otras instituciones municipales, como escalones primeros en la percepción del poder desde abajo. La mayoría de los estudios de ayuntamientos de que disponemos son análisis meramente institucionales, económicos o de puta gestión, pero falta por conectar las relaciones de ambos espacios de poder, el municipal de los ayuntamientos y el provincial de las diputaciones, muy conflictivos en gran par-

Hispania, LIX/1, núm. 201 (1999) 9-36 
te del periodo contemporáneo, pero en todo caso marcos de relaciones decisivas en la construcción del poder local.

La importancia de lo municipal en la construcción del poder está aún por descubrit. Los Ayuntamientos fueron el espacio natural y primario donde se practicó el caciquismo más elemental y espontáneo, primer eslabón, a veces embrionario y rudimentario, de la cadena de mediatizaciones del poder en la España de la Restauración. Era donde se manejaban los recursos de poder y privilegio más directos e interesantes para el ciudadano, la gestión de los Ayuntamientos a cargo de las élites era precisamente la que dejaba amplios márgenes para el aprovechamiento privado de los bienes públicos. Esta importancia de las esferas locales del poder derivó, entre otras razones, del alto grado de autonomía real que en su funcionamiento tuvieron instituciones como juzgados municipales y de primera instancia, así como por la transcendental incidencia de muchas de sus actuaciones sobre la vida cotidiana de los vecinos, sobre las estrategias de poder y de reproducción social de las oligatquías, como recordatá más adelante Cruz Artacho. Autonomía real de acción que incluso recibió el espaldarazo del liberalismo decimonónico de corte progresista al considerar al ayuntamiento como vía directa de participación del ciudadano en la cosa pública, así como el "primer cimiento del gobierno interior de la nación»" ${ }^{18}$.

Las competencias municipales desde 1877 eran extraordinarias, entonces la gestión municipal constituía la pieza básica del mapa administrativo del Estado liberal español. Valga esta relación de algunos cauces de decisión más importantes del poder local, como concretaba hace años R. Carr ${ }^{19}$ : determinación y aplicación de los impuestos, distribución de los servicios del Estado, acceso a la enseñanza y la beneficencia, abastecimientos, explotación de montes y bienes comunales, préstamo de los pósitos, talla, reclutamiento y exención de los quintos; los Ayruntamientos eran también centros de colocación para enchufados y ejercían influencia con las contratas de suministros, dotación de infraestructuras de transporte, arrendamientos de funciones y servicios, manejo de los guardias de consumos y paso franco, pago a paniaguados, impago o despido del maestro local, compra de aceite malo para los faroles, confusión de caminos particulares con calzadas públicas, contrata de trabajadores en obras públicas durante las elecciones, información confidencial al cacique por parte de los secretarios, préstamo del pósito sin creces y sin reintegro, agios, cuentas falsas, presupuestos arreglados o ventas de comunales. Podín elaborar la lista de los productos (de comer, beber y arder) incluidos en los impuestos de consumos (que no pudieron abolirse hasta 1911) y recargar sobre ellos a veces hasta un cien por cien; los alborotos y huelgas en fielatos eran una de las fuentes de conflictividad del periodo. Sus problemas de finales de siglo se complicaron con el aumento demográfico, con la intensificación de la remodelación urbanística, con los servicios básicos de vigilancia de mercados, cementerios, abastecimien-

\footnotetext{
18 Asi lo recoge S. CRUz ARTACHO en su articulo siguiente, citando a C. CASTRO, El régimen municipal tiberal en España. Madrid, 1979, 62.

1) CARr, R., España: de la Restauración a la democracia, 1875-1980. Barcelona, 1995.

Higpania, IJIX/1, num 201 (1999) 9-36
} 
tos, alumbrados y transporte, con la acogida de la abundante inmigración que generaba barrios periféricos abandonados, para los que había que habilitar hospitales, hospicios, servicios de sanidad y asistencia. En todo caso, era necesario proporcionar alimentos de primera necesidad asequibles y trabajos en los meses difíciles de invierno. La penosa situación económica de las clases populares, que a veces vivian de estos servicios, les hacía especialmente vulnerables y dependientes del poder local. Todas eran formas de intercambiar servicios públicos por favores privados. Los partidos turnantes consienten estas corrupciones y tienen un pacto de silencio, estas prácticas tampoco estuvieron ausentes de los partidos republicanos ni de los regionalistas; de aquí que todos los reformadores comenzaran por el intento de modificar la legislación de la administración local.

No vamos a realizar un análisis de las elecciones municipales en la región, pero sí debemos incorporar estos comicios a los mictoanálisis de las zonas propuestas. La dinámica electoral municipal parece que siguió una trayectoria distinta de la general y que en varias ciudades se impuso una creciente independencia del electorado al margen del gobierno; aquí sí que los resultados podían depender en muchas ocasiones de la fuerza de la oposición y la capacidad de movilización de su sociedad. La renovación de los concejales pot mitades cada dos años y la división en pequeños distuitos electorales dificultaban obtener grandes resultados, pero permitieron que las campañas municipales fueran verdaderas escuelas de localismo y de movilización para los electores y de aprendizaje político para los elegibles. Eta precisamente el Ayuntamiento el escenario donde se desarrollaba lo más trascendental de toda elección: él elabora las listas electorales y regula el proceso en sus primeras fases, los alcaldes presidían las Juntas municipales del Censo y encabezaban las mesas electorales y los sectetatios municipales, empleados a voluntad del consistorio, eran los agentes operativos con más capacidad de intervenir en el proceso. Las luchas electorales en los ámbitos municipales a veces tenían poco que ver con los ritmos generales del país, con el turno o con los problemas que parecian más acuciantes en el plano general, se movian por redes y grupos más inmediatos, se copaban en grandes familias o sagas que controlaban la sucesion del poder, se mezclaban con los patrimonios y negocios más importantes de cada lugar y ofrecian una cara del poder muy fragmentada, pero muy operativa y eficaz a la hora de condicionar decisiones de gobierno municipal o beneficiarse de los equipamientos o recursos conseguidos del Estado o de la provincia. Hay que recordar que hasta 1909 no se retiró a las autoridades municipales del proceso electoral general.

Los juzgados y las juntas municipales son otros tantos escenarios cuya atención es básica. Las competencias reconocidas a los juzgados municipales tanto en materia civil como penal ${ }^{20}$ afectan a la esfera individual de los vecinos (estado civil, capacidad jurídica, represión de faltas,...) y a la reproducción de sus patrimonios (testamentarias, herencias,...).En relación con este poder judicial municipal estaban las acciones de vigilancia y represión de la Guardia Civil que, como se-

20 Cruz ARTACHO, S., Caciques y Campesinos. Poder politico, modernización agraria y conflictividad rural en Granada, 1890-1923. Córdoba, 994, 308.

Haspania, L.JX/1, núm. 201 (1999) 9-36 
ñala Cruz Artacho para Andalucia, representaban por una parte la presencia ejecutiva del Estado en estos ámbitos y de otta tenía encomendadas funciones subsidiarias de auxilio a la justicia municipal. La conclusión de Artacho ${ }^{21}$ es que «fueron importantes las actuaciones partidarias e interesadas de los juzgados y alcaldías, las conexiones familiares entre los gestores de estas instituciones de poder, así como el papel estelar que desempeñaron en la consolidación y preservación de un orden social injusto en muchas comunidades rurales». $\mathrm{La}$ influencia sobre estos Ayuntamientos la ejercían a partes iguales los concejales, aprendices de políticos vinculados a las fuerzas económicas e instituciones más vigorosas de la ciudad, y los mayores contribuyentes, entiquecidos por la desamortización y los procesos de urbanización pasados; ambos formaban las juntas municipales que confeccionaban presupuestos, impuestos, de forma que la práctica clientelista es la que condujo habitualmente su comportamiento en la administración.

Los distritos electorales son el segundo escalón de esta territorialización del poder. El distrito es el medio natural de enraizar el poder, por eso la importancia del distrito es clave. Primero en el orden material, en el sentido de que la procedencia, el domicilio, la ubicación de la propiedad, los cargos que ejercen en él los detentadores del poder local marcan ya un lazo físico verdaderamente importante para explicar la vinculación de casi todos sus protagonistas al territorio de actuación. Peto no sólo en esta dirección es fundamental el influjo del distrito, más de la mitad de los distritos de la región son casi propiedad de familias o grandes personajes que se suceden en el escaño o controlan su elección fácilmente. Estos mecanismos electorales debieron ser fundamentales tanto para acceder al poder local como para mantenerlo y reproducirlo después. Hemos de tener en cuenta que las elecciones provinciales se realizan en el mismo marco que las generales, y de aquéllas depende el régimen de los ayuntamientos rurales en gran medida.

El caldo de cultivo de las redes del clientelismo es también el distrito. Éste es el ámbito donde se establecen ante todo las relaciones primarias de familia y amistad, pero también se ubican en este marco las redes de clientelismo tal vez más fuertes y estables, ya sea por medio de la vinculación a intereses económicos (desde los renteros a los obreros de una fábrica), o bien por medio de instituciones de poder local, o particularmente a través de estrategias familiares y una estrecha red de relaciones sociales de prestigio e influencia personal.

Es finalmente el medio natural donde se legitima y socializa el poder. El distrito es el segundo eslabón de la cadena que une al actor del poder local con su sociedad, es el ámbito más genuino del pattonazgo, se entabla casi una relación parafamiliar entre el edil y sus representados. Se hace preciso desde ahora prestar mucha más atención a esta relación primaria y aplicar el microscopio a las redes de lazos territoriales de los representantes del poder local.

\footnotetext{
21 Ciruz Artacho, S., Ibid.
}

Hiqunie, LIX/1, núm. 201 (1999) 9-36 
La Iglesia local y los arciprestazgos representan otro ámbito local de trascendencia en la construcción del poder local, al menos en Castilla. La testimonial presencia de la Iglesia entre los representantes del poder político es un aspecto del que nos hemos ocupado sólo parcialmente en nuestro anterior proyecto de investigación sobre las élites, pero cada vez somos más conscientes de la importancia del factor religioso. Esta intetacción entre el poder y lo religioso se produce tanto en el sentido de la influencia que la explícita militancia en organizaciones confesionales o el apoyo a sindicatos católicos -tan extendidos en nuestra región- pudo tener en el curriculum de algunos protagonistas del poder local, como en el del lugar que el propio clero tuvo en la captación de voluntades o en la organización del aparato caciquil en determinados distritos. Nuestro análisis se va a centrar ahora en Ciudad Rodrigo, un ámbito donde esta interferencia eclesiástica es especialmente notable. Pero en todo caso es necesaria la contemplación de la Iglesia de cada lugar en la configuración del poder local. Sin conocer su influencia no entenderíamos la cultura política del campesino castellano.

Provincia y Diputación han sido ya lugares comunes en los análisis del poder, pero aquí queremos insistir sobre todo en el provincialismo. La provincia se muestra efectivamente como el tercer escalón natural del poder local. Como hemos concluido analizando el poder de las élites castellanas, el marco y el significado de la provincia es otro de los factores de definición y el ámbito por excelencia de construcción de su poder. Ello obedece sin duda a las profundas raíces que ha echado el nivel provincial de la pirámide administrativa liberal en esta región, la importancia de instituciones como Diputaciones, Gobiernos Civiles, diversas juntas provinciales, el protagonismo de las capitales de provincia concentrando juzgados, dependencias militares, eclesiásticas, educativas, sanitarias, etc., que llegaba a articular la vida de las diferentes comarcas y a crear una identidad provincial por encima de cualquier otro signo de definición.

Ya hemos destacado repetidamente las Diputaciones como escuelas y escenarios de poder. Hemos puesto de relieve la importancia de las Diputaciones 22 como canteras de parlamentarios, como plantel de concejales y alcaldes, como escuela de políticos locales y como plataforma desde donde ejercer de forma práctica ese poder tan entaizado en lo local. Queda por determinar, y en ello estamos trabajando, cuál es la razón de que la élite política general entronque más fácilmente con las elecciones provinciales y la Diputación y, sin embargo, se produzca un relativo alejamiento entre esa élite política general y los alcaldes y concejales. Es preciso repetir que desde la institución provincial se controlaba en buena medida los Ayuntamientos rurales, se organizaban los niveles intermedios de la elección indirecta de senadores por compromisarios y se dirigía todo el proceso electoral, tanto general como municipal de la provincia. En cualquier caso, suele haber situaciones de compromiso y pacto, como la sucedida en Valladolid, donde las élites políticas parlamentarias se repartieron ordenadamente esferas de influencia entre el gamacismo en la Diputación y el albismo en el Ayuntamiento.

22 Carasa, P.- PELAZ, V., «Diputaciones y oligarquías provinciales. Salamanca: 1976-1923» en I Congreso de Historia de Salamanca. Historia Contemporánea. Salamanca, 1992, págs. 133-154.

Hipunia, LIX/1, núm. 201 (1999) 1)-36 
Una atención especial reclaman los gobernadores civiles, que desgraciadamente no hemos podido analizar con el detenimiento que merecen por la práctica desaparición (u ocultación) en la región de los archivos de los Gobiernos Civiles. Como dijimos en su día, creemos que no deben englobarse en el análisis de las Diputaciones, porque rara vez ejercen el poder en la provincia de la que son naturales; parece que no se trata de un mecanismo para ejercer el poder en su distrito, sino un premio por su labor La relación del gobernador civil con el poder local tiene unas características especiales, que bien pudieran ser exactamente contrarias a las de la Diputación, y puede tesultar, por el contrario, un buen termómetro para analizar hs tensiones entre el poder local y el central. En el mejor de los casos, deberemos prestarles atención en alguno de los microanálisis urbanos que estamos realizando, conscientes de la fuerza que detentaban a la hora de transmitir las órdenes del ministro en los procesos electorales y de la trascendencia de su eslabón en la cadena del caciquismo; todo ello debió tener efectos importantes en el ejercicio del poder local.

La prensa local es otro elemento básico y territorial del poder local. Ya es conocido que la prensa castellana ha actuado de vivero de políticos y arma de partidos en el caso particular vallisoletano. La prensa aparece también desde luego como un instrumento clave para los sujetos del poder local. Habíamos descubierto ya estas conexiones entre los parlamentarios de León, contemplamos también en otra ocasión el caso más relevante de Valladolid donde numerosos miembros de la élite o bien ejercían el periodismo o bien se sentaban en el consejo de Administración de los periódicos locales, fundamentalmente de El Norte de Castilla que se convirtió en una verdadera cantera para la clase politica vallisoletana, en una plataforma excelente para acceder al poder o perdurar en su ejercicio ${ }^{23}$. En cada uno de los ámbitos elegidos para el microanálisis local abordaremos este elemento constructor del poder local.

\subsection{El poder relacionado: se reproduce y practica a partir de conexiones con el entorno}

Entender el poder de forma relacional, valorando su dimensión social sobre todo, es otra manera de explicarlo mejor. Un descubrimiento tan simple como la consideración del hombre no sólo como sujeto sino también como objeto del poder, entendido éste en su más elemental significado (capacidad de un agente para influir en la conducta de otros), nos exige incardinar su análisis en la comunidad que lo envuelve y en las relaciones y redes primarias que genera en su entorno. Esto implica que no puede limitarse la atención a los sujetos del poder, sino que es preciso conocer los grupos y sectores sociales sobre los que influyen, que no son en modo alguno simples teceptores

23 Los trabajos de C. AimetÑ $\wedge$, desde su tesis doctoral, pasando por artículos posteriores y las tesis doctorales por él dirigidas han insistido en este particular y han aclarado convenientemente estas relaciones.

IIipunia, LIX/1, núm. 201 (1999) 9-36 
de influencia, sino que entran en interacción con ellos y resultan tan importantes como aquéllos en la explicación cabal del poder. Se ha producido un abandono de este carácter relacional básico del poder en la historiografia española de la Restauración. Los historiadores han ofrecido un dibujo muy elaborado de su relación por arriba con el poder instituido y una imagen mucho más diluida de sus contactos inferiores con la sociedad local. Por esto resultan extraordinariamente fructiferas la historia local y la prosopografía, pero sobre todo la microhistoria para desentrañar la naturaleza compleja del poder.

Se han solido señalar tres niveles de relación, vertical inferior, vertical superior y horizontal. A nosotros nos ha interesado especialmente la conexión de estos sujetos del poder con la parte inferior de su comunidad, las clientelas y dependencias de diferentes tipos que les aseguran un fuerte apoyo social y les posibilitan asentarse firmemente en sus respectivas comunidades. Tratamos de descubrir las redes compactas que forman entre sí, organizadas sobre la base de relaciones familiares, profesionales y económicas, que no se definen en términos clientelares, pero en las que sí existe cierta jerarquización. Tampoco olvidaremos el tercer nivel de relaciones ya más secundarias y formales, por el que consiguen conectar con las instancias del poder central de donde se nutren y extraen su capacidad de decisión.

Por lo que se refiere al nivel vertical inferior, el papel de los gobernados en la configuración del poder es tan importante como desconocido. Como hemos repetido, la reciente tesis doctoral de uno de los miembros del equipo investigador ha analizado el poder de las élites palentinas ${ }^{24}$ insistiendo con gran rigor y originalidad en la componente primaria del podet, y cuestionando, por el contrario, las relaciones formales del poder como mucho menos importantes y limitando de forma especial ta influencia del clientelismo. Nosotros participamos de estas conclusiones, pero no estamos seguros de que la última afirmación sea igualmente cierta, en cualquier caso trataremos de comprobarlo. Aparte de la validez explicativa de este tipo de relación formal y del clientelismo, de lo que pretendemos dar cuenta aquí es de que no se ha estudiado el papel de los grupos populares no elitistas ni dirigentes en la configuración del poder local y de los efectos que en las élites y en la naturaleza del poder provocan sus reacciones, resistencias y estímulos; nosotros partimos del supuesto de que las respuestas sociales fueron muy importantes en la configuración de este tipo de poder, puesto que no son sólo fruto de una desmovilización, sino también producto de una cultura de resistencia a la dominación, tanto en ideas como en actitudes ${ }^{25}$.

Es evidente que el nivel puramente horizontal no ha sido convenientemente estudiado, porque se ha identificado exclusivamente con las relaciones de sociabilidad formal de asociaciones, partidos, ligas o movilizaciones colectivas; peto existe otro mundo diverso de estas relaciones horizontales que es más pri-

24 J. VILLA ARraz, Las élites y el poder...

25 Cfr. SCOT'T, James C., «Patronazgo o explotación?n, en Eirnest GlaLJNLR (y otros), Patronos y clientes en las sociedades mediterráneas. Madrid, 1985, pp. 35-61, especialmente su aportación sobre las armas de los débiles.

Hi.pzrnia, LIX/1, núm. 201 (1999) 9-36 
mario y elemental y que contribuye francamente a la construcción del poder local. Abordaremos, pues, esas redes compactas formadas entre sí, organizadas sobre la base de relaciones familiares, profesionales y económicas, que no se definen en términos clientelares, pero en los que sí existe cierta jerarquización y en todo caso transmiten y crean poder. No olvidaremos por ello las grandes movilizaciones, como fue el proteccionismo, que ya hemos valotado en otra ocasión ${ }^{2 k}$, por medio del cual los cerealeros castellanos sí que lograron conectar con otros ámbitos en este nivel horizontal. Entonces descubrimos cómo bajo este movimiento latían fuertes influjos sobre los comportamientos políticos, este tipo de movilizaciones debió alterar la forma de concebir y de practicar el poder local en Castilla.

El nivel vertical superior de dependencias y jerarquizaciones y el más formal de los partidos y las redes administrativas es el mejor conocido y no por ello hemos de abandonarlo para complementar las direcciones anteriores. Por medio de este tipo de relaciones consiguen conectar con las instancias del poder central de donde extraen capacidad de decisión y generan de esa forma un haz de relaciones que hace referencia al Estado, la administración, los partidos, el asociacionismo, etc. Por medio de estos mecanismos son capaces de llegar al poder, de aumentatlo y mantenerse, de reproducirse y de conseguir en definitva organizat una elite provincial.

Además de esta dimensión más física e institucional, deberemos abordar cuál es el papel que el Estado juega en la construcción del poder local. El que apostemos por una vía ascendente en la construcción y análisis del poder no debe excluir el impacto que la relación con el Estado produce en el poder, porque éste, como hemos reiterado, es el resultado de una interacción, de un diálogo, no sólo con la base de la sociedad, sino con la cúpula del poder institucional, una relación que no sólo hace referencia a los dictados, influencias directas y exigencias del poder superior, sino también a las percepciones negativas, tesistencias y teacciones que produce, tanto en las élites intermedias como en la sociedad. El Estado muchas veces adopta las formas que el poder local impone, Toscas insiste con razón en este aspecto en el artículo siguiente.

También hay que considerar la dirección vertical superior de hacer descansar parte de la naturaleza del poder en su necesidad de generar relaciones de dependencia con la Administración central y provincial. Numetosos autores han señalado que el poder local ha tenido tanta importancia en la construcción contemporánea del Estado en España porque ésta ha tenido una dimensión más administrativa que política. La esfera del ejercicio de poder y las funciones políticas se canalizaron por la gestión de secretarías de ayuntamiento, munici-

26 P. CARASA y otros, ¿La movilización cerealista castellana y los precedentes del 98. Del proteccionismo al regeneracionismo", en J.P. Fusi y A. Niño, Antes del "desastre». Origenes y antecedentes de la crijis del 98. Madrid, 1996, 9-39.

Hijpunia, JIX/1, núrn. 201 (1999) 9-36 
pios, diputaciones, juntas y delegaciones provinciales. La Administración se había convertido así en el único cauce de comunicación entre el Estado y la sociedad, pero no sirvió tanto para vertebrar una sociedad y aproximarla al Estado, cuanto para utilizarla de plataforma de intercambio y de consolidación de elementos intermedios que mediatizaban y se beneficiaban de esa dificil relación. Obviamente, este canal administrativo obligado ha modelado el poder, le ha exigido adaptarse al receptáculo, ambos se han construido en una interacción que les ha condicionado a los dos.

La realidad de los partidos, como elemento de relación formal y secundaria, dentro de la dimensión horizontal, está hoy menos valorada a la hora de analizar los componentes del poder. Pero tampoco podemos caer en el extremismo de creer que los partidos políticos no tuvieron importancia como medios de construir y ejercer el poder. Rebajando la anterior consideración de ser casi los únicos escenarios donde actuaban los amigos políticos, aún debemos contar con este factor en el microanálisis del poder, aunque seguramente debamos intensificar el microanálisis de los partidos y las relaciones cuasi primarias dentro de ellos, por encima de las estructuras formales e institucionales.

$\mathrm{El}$ asociacionismo patronal es otro ámbito de interés en la construcción formal del poder local, igualmente en el nivel horizontal. Ha sido un movimiento que habitualmente se habia matginado del análisis del poder político y discurría solamente por los senderos de la sociabilidad o de la economía, pero es evidente que ha de incluirse también en este marco del poder local. Las experiencias investigadoras que se llevan adelante en nuestro entorno ${ }^{27}$ señalan importantes conexiones que no han de estar ausentes en el análisis del poder local.

El poder local finalmente es fruto del dinamismo de la sociedad o expresión de su inmovilismo? Contra la tendencia a sobrevalorar los aspectos de continuidad en las estructuras de poder local, hoy se tiende a subrayar la frecuente discontinuidad, y para ello parece necesatio examinar el problema comparativamente en medios territoriales diversos y en periodos cronológicos que superen el corto plazo, como hace E. Toscas en su trabajo adjunto. El análisis del poder local, que suele interpretarse como producto de la inmovilidad de la sociedad local, puede plantearse exactamente a la inversa: como una manifestación política de la movilidad y fruto de cierto dinamismo social dentro de estas comunidades locales.

Serán objeto de nuestra atención, en busca del efecto de esta movilidad, los movimientos populares (como socorros mutuos, sociedades de resistencia, sindicatos), asociaciones y ligas patronales, centros de sociabilidad (desde Círculos, Ateneos, hasta Casas del pueblo), y centros culturales locales en su

27 P. Calvo CabnLlero se halla realizando su tesis doctoral sobre este particular en Castilla y ha adelantado ya algunas conlusiones, como p.e. «En torno a un debate: La lógica del comportamiento asociativo patronal. El caso de la patronal castellano-leonesa durante el primer tercio del siglo XX, en Investigaciones Históricas, 12 (1992) 285-300.

ILipunia, LIX/t, núm. 201 (1999) 9-36 
relación con los procesos de construcción del poder local. Sin duda son éstas las vías por donde discurren los influjos de esa interacción entre poder y sociedad que siempre nos ha parecido tan decisiva. Ha sido frecuente analizar las acciones del poder central sobre ellos, o incluso las resistencias que pueden haber ofrecido ante esas acciones, pero lo que no ha sido objeto de análisis es el influjo que esta interacción ha generado en el poder mismo, cómo éste ha respondido o se ha adaptado o modulado de acuerdo con algunas de estas exigencias.

\subsection{El poder asimilado o rechazado: la cultura politica de poder local}

Nos debemos adentrat, por fin, en otro conjunto de aspectos de tipo más simbólico y representativo que hasta ahora no ha sido analizado; conviene tener en cuenta actitudes propias de la cultura política y descubrit la influencia que sin duda han ejercido en la concepción, ejercicio y aceptación o rechazo del poder local por parte de la sociedad que lo soporta ${ }^{28}$. Si hemos definido el poder como el resultado de una interacción entre quien lo ejerce y quien lo obedece, es lógico que realicemos el intento de acercatnos al conocimiento de sus integrantes culturales, simbólicos e imaginarios, a pesar de las dificultades que entraña tanto en su metodología como en su documentación.

Dentro de estos imaginarios populates destaca la peculiar representación del Estado. Desconocemos, en esta dirección apuntada, la recepción que el pueblo tenía del Estado, de sus attibutos y funciones. Es bastante probable que la primera percepción que el pueblo tuviera de la autoridad y el poder político se relacionara más con lo local que con lo central, es más, no es absurdo pensar que la idea de Estado existente en la mentalidad popular tuviera que ver sólo con esta sensación del poder local en los Ayuntamientos. Sería preciso conocer cómo ha evolucionado en la cultura popular el concepto de Estado, es probable que estemos extrapolando sin demasiada justificación una manera de comprender lo estatal, expuesta por los partidos y por quienes tenían capacidad de publicar su ideas de forma impresa, bastante ajena a las mentes de los receptores de sus órdenes e impuestos.

La historiografia ha sobrevalorado la fuerza del Estado liberal y ha menospreciado la del poder local. Sabemos también que el Estado español, a pesar de sus pretensiones centralizadoras y nacionalizadoras, fue todavía durante toda la Restauración bastante débil, lo cual se relaciona con la existencia de una considerable fragmentación del poder, pues a los dirigentes no les quedaba más re-

28 Acaba de aparecer un estudio colectivo que aporta sugerencias en este sentido, aunque son escasas las referencias a lo estrictamente politico y al poder y sus representaciones; cfr. R. Cruz - M. Pérez Ledesma (Eds.), Cultura y movilización en la España Contemporánea. Madrid, 1997.

Hi.pania, LIX/1, núm. 201 (1999) 9-36 
medio que pactar con unos poderes locales de cierta importancia. El proceso de construcción del poder tiene, pues, esa doble y ya señalada dirección descendente en el diseño y ascendente en la edificación, por ello metodológicamente ha de tenderse en esa dirección (con doble sentido) de análisis del poder, que se sitúa precisamente en los orígenes y los destinatarios locales. Pero el Estado no sólo ofrecía una debilidad administrativa, fiscal o política frente a la sociedad, sino que su mayor fragilidad era de tipo mental, una escasa credibilidad que generaba multitud de contradicciones y resistencias en las mentes populares. La elaboración teórica del concepto de Estado-nación parece que sufre un proceso de disgregación desde el siglo XIX al XX, que sin duda debió ser muy diferente en la mente de las élites periféricas, en la de los grupos populares de esa misma periferia, que la experimentada en las mentes de las élites castellanas y particularmente en la forma de concebirlo los campesinos de Castilla. También esta orientación ha de atenderse en la investigación del poder local.

Es importante asimismo, no ya la inmediata percepción del Estado, sino más en general la manera de comptender la autoridad desde el escenario local. Existió asimismo un concepto de autoridad y una valoración de la misma que nos resulta hoy prácticamente desconocida. Este sentido de la autoridad, que principalmente se alimentaba en la relación directa e inmediata con el poder local, debía componerse de múltiples percepciones negativas que incitaran a la resistencia, de otros sentimientos de resignación y posibilismo que llevaran a la sumisión y aceptación interesada. Pero no es menos cierto que el poder mismo trataría de difundir la idea que de sí mismo quería transmitir y encontratía desde arriba numerosas vías de prestigio y legitimación para hacerse eficaz y asimilable frente a los gobernados. Cuántas ideas y mensajes de la cultura de las élites políticas, especialmente de las locales, iban encaminadas a imponer o hacer asumible su liderazgo, su autoridad. Se sirvieron de numerosos argumentos que hoy a nosotros nos parecen inocentes y cuyo profundo simbolismo no acertamos a descubrir.

Así sucede, por ejemplo, con la idea de los intereses comunes bien defendidos, de la consecución de favores institucionales para la ciudad o el pueblo, del aumento y superioridad del prestigio local, de la subordinación de las influencias exteriores y su rentabilidad, la idea misma del partido y de la ideología. Otra de estas representaciones asociadas al poder por las propias élites, sin duda, era la riqueza material y un importante patrimonio; después de todo el bombardeo de concepciones plutócratas y de gobierno de los mejores que había recaído sobre el pueblo, esta supuesta identidad de riqueza y poder tenía el efecto añadido no sólo de incrementar la riqueza por medio del poder, sino sobre todo de legitimarlo, hasta el punto de que el propio pueblo encontrara inadecuado que un desposeído ocupara el poder, y en todo caso hallara lógico que cuanta más riqueza poseyera el poderoso dentro de ese territorio con mayor ahínco defendería los intereses de la localidad. Estos mensajes causaron un efecto justificador importante y constituyeron una de las razones que pueden llegar a explicar cómo el caciquismo se enquistara durante más de un siglo fundamentado en la propiedad y los recursos financieros. $Y$ al contrario, puede ex-

Hiphanid, LiX/1, núm. 201 (1999) 9-36 
plicar la identificación simple del poder político con el económico que realizaron primeto los regeneracionistas y han continuado luego otras escuelas interpretativas del poder. La confusión entre poder político y poder económico no es sólo una idea historiográfica del materialismo histórico, antes había sido una realidad histórica en la mentalidad popular convenientemente acuñada por la propia élite y asumida por casi toda la sociedad durante la Restauración. Por eso mismo, debió estar siempre contrapresada con la oposición de intereses y el rechazo de la subordinación económica como arma de resistencia de los gobernados. Es necesario, pues, analizar cómo se mezclaba en la mente de los campesinos o de las clases populares urbanas la política y la riqueza, en qué proporción se justificaban mutuamente y en qué otra medida se excluian y resistran entre si.

El significado del territorio en la concepción castellana del poder va más allá del que se ha concedido tradicionalmente a la tierra. Históricamente en Castilla ha sido muy fuerte la conciencia del territorio y sus efectos sobre la cultura política no son bien conocidos. Por ejemplo, los efectos de la organización político-espacial en la cultura política fueron extraordinarios. Nosottos siempre hemos considerado que la reforma administrativa y territorial de Javier de Burgos había constituido uno de los pilares fundamentales de la construcción política desde arriba, no sólo de la morfología de las ciudades capitalinas tan importante y decisiva, sino en la capacidad de aglutinar identidades y fidelidades bajo la categoría de lo provincial, hasta tanto que paradójicamente acabó reforzando las tendencias localistas más propias del antiguo régimen. Es probable que algo que nació exactamente con la idea teórica de superar los espacios estancos y autárquicos tradicionales por medio de la centralización fiscal y política y que tendía a fortalecer la idea de un Estado, no sólo no alcanzara su objetivo, sino que consiguiera precisamente lo contrario, consolidar las viejas tendencias localistas, proporcionarles un cauce intermedio compatible con la estructura estatal superior y estimular las inercias de lo local como prioritario. La fuerza de la procedencia y naturaleza, de la propiedad y el patrimonio enraizado en un ámbito geográfico que se funde con la persona y la familia, la vecindad e identidad local, la rivalidad y contraposición de los núcleos próximos era $\tan$ fuerte que condicionaba cualquier otro elemento que tratara de superponérsele $y$, aunque en muchas ocasiones este actor superior y central consiguiera establecerse, acababa con una victoria pírrica por la cual recibía más influencias de las que era capaz de transmitir.

Asimismo podemos preguntarnos cuál era la conciencia de identidad y las improntas que cada núcleo de población aportaba a la configuración del poder. Es probable que en cada localidad funcionatan unos resortes especiales, unas señas de identidad, una memoria histórica, una experiencia de familias y líderes, incluso unas características físicas (aislamiento o comunicación, llano o montaña, interior o costa), un funcionamiento del mercado y abastecimiento (fronteras, autarquías, contrabandos), una influencia de las políticas fiscales y del reparto discriminado de favores, que condicionaban la respuesta y la relación política con el poder local y por ende la naturaleza del mismo. 
La aceptación popular de las instituciones locales es otro elemento de cultura política que afecta a la construcción del poder. En este proceso de conformación del poder local jugaron un papel simbólico e identificativo muy importante las instituciones locales, principalmente la Diputación y los Ayuntamientos, como hemos repasado más arriba. Conocemos bien aspectos institucionales, políticos, hasta personales y de partido de esta influencia, pero convendría desentrañar qué mecanismos mentales de rechazo o justificación, qué sensaciones y qué resistencias o solidaridades se desencadenaban en las clases populares urbanas cuando se mencionaba la palabra ayuntamiento, ordenanza municipal, concejal o alcalde. De semejante manera sería muy interesante conocer qué sensación producía en los alcaldes rurales la palabra Diputación, con qué sentimientos y actitudes se relacionaba, a qué efectos políticos o económicos se asociaba, cómo percibían su imagen y su función. En contraposición con estas percepciones, o probablemente de acuerdo con ellas y transigiendo con muchas de estas demandas, se definían los objetivos del poder local, se diseñaban sus estrategias, se determinaban las personas que lo detentaban. Las élites que regentan estas instituciones no sólo actúan movidas por sus propios intereses, sino que se amoldan en muchas ocasiones a los efectos que sus acciones vayan a provocar en los gobernados. En este sentido convendría conocer por qué se aceptan estas instituciones entre las comunidades y cómo se argumenta su autoridad, cuál es la percepción de imágenes, el mensaje simbólico de la autoridad, la mitificación y desmitificación de sus protagonistas.

El papel que antes se concedía a la dialéctica del conflicto era probablemente excesivo por considerarse exclusivo y determinante, pero no puede abandonarse este factor en la composición del poder; entre otras manifestaciones importantes esta actitud ha generado entre las clases populares una cultura de la resistencia. A pesar de tantos estudios sobre conflictos, aún nos resulta especialmente ignorada esta cultura resistente del pueblo. Qué evolución sufre, con qué argumentos iniciales se construye, qué representaciones mentales desvelan sus comportamientos, qué efectos produce en los que mandan y en su manera de ejercer el poder la cultura de la resistencia entre los grupos populares, son preguntas aún sin respuesta. Estamos demasiado acostumbrados a analizar los motines y los conflictos en una única clave socio-económica, que no deja de ser importante, pero no es la única. El conflicto es también una forma de modelar el poder político tan importante como la obediencia, es capaz de obligar a los protagonistas que toman decisiones a adaptarse en sus formas de comportamiento, a adoptar estrategias de cesión, a modificar lentamente la tendencia inherente a todo poder a excluir la participación, a utilizar argumentos y legitimaciones tradicionales mezcladas con nuevas motivaciones. Y quien habla del conflicto como instrumento de modelar el poder local puede referirse a continuación a la violencia como otro instrumento relacionado con el ejercicio del poder, no sólo la descendente y coercitiva, sino la ascendente y reivindicativa, en esta áspera interacción también se modelaron algunas características del poder local. 
El difícil discernimiento entre lo público y lo privado es otra notable cuestión que atañe a la cultura política y su capacidad de modelar el poder y que no sólo no es bien conocida, sino que se presta a innumerables equívocos e imprecisiones históricas. Es importante y no bien destacada la percepción de los ámbitos del poder por parte de los diferentes grupos de la sociedad y la demarcación conceptual de sus funciones y competencias. Seria muy conveniente adentrarse en lo que significaba la noción de lo público y lo privado entre el pueblo. Incluso estas dos esferas no estaban bien diferenciadas entonces en la mente de los dirigentes, por eso caemos en frecuentes anacronismos cuando contraponemos estos valores en las circunstancias históricas de la Restauración. Convendría, pues, estudiar las peculiares relaciones de lo público y lo privado dentro de los detentadores del poder. Sabemos que la percepción de lo privado centrado en la familia, el patrimonio, los propios intereses y negocios no tenía una clara solución de continuidad cuando se trataba de ejercer el poder político, por ejemplo en la Castilla de la Restauración; sería interesante percibir en qué medida avanza la separación de estos dos mundos, que bien pudieron experimentar un lento y resistente distanciamiento, casi en los mismos términos en los que se producía el dificultoso discernimiento entre los sagrado y lo laico.

Las pervivencias mentales en la legitimación del poder fueron muy largas y muy hondas. Más dificiles de investigar, pero no por ello menos decisivas en la construcción del poder local, han sido las herencias tradicionales legadas a esta cultura política de la primacía de lo local. En primer término, la conciencia de la familia y su papel como vehículo y depositario de poder es una de esas pervivencias que ha sobrevivido durante un tiempo relativamente limitado aplicada al poder político ejecutivo y administrativo. Nos puede ayudar a comprender esta vieja prolongación el hecho de que esta pertenencia del poder en exclusiva a una familia haya permanecido durante un tiempo mucho más largo y siga vigente aún aplicada a la Monarquía. Es una inercia heredada del Antiguo Régimen vincular tradicionalmente a una familia concreta la legitimidad de una sucesión dinástica, se trata sin duda de una fuerza inerte de difícil superación en muchas sociedades. Decíamos que nos puede servir para identificar como una persistencia de Antiguo Régimen la vinculación del poder politico a una familia el hecho, absolutamente extraño e incluso contrario a nuestra cultura actual, de que la legitimidad de la jefatura de un Estado descanse en una familia dinástica que la detenta casi como un mayorazgo político, con la añadidura de que se transmite preferentemente por vía masculina. Son elementos incomprensibles desde una posición ahistórica, que repugnarían el más común de los sentidos políticos de nuestro mundo, y sin embargo las jefaturas del Estado se transmiten por esta vía con normalidad en muchas sociedades actuales. ¿Por qué esta misma idea, que entonces era aplicada al poder político de las élites locales y nacionales con toda naturalidad, se ha abandonado para el resto de los ámbitos políticos y persiste sólo cuando se trata de las Monarquías? Es necesario redescubrir esta vieja importancia del renombre de una familia, de sus rivalidades con ottas, o de la mitificación de los linajes, a la hora de configurar el poder local.

Hippania, J_IX/1, núm 201 (1999) 9-36 
Siguiendo con estas prolongaciones del Antiguo Régimen, otra pervivencia no suficientemente conocida y muy mezclada con el poder político es el mensaje religioso, que se mantiene fuerte y se enfrenta al secular Estado libetal. Si dificil y lenta fue la separación de los dos mundos trascendente y material, si costó siglos alcanzar la secularización de las costumbres de la vida cotidiana, no menos dificultoso resultó desacralizar primero y laicizar después el poder político en las esferas locales. Y si esta característica antigua del poder político tiene alguna vigencia es precisamente en el ámbito castellano, la presencia influyente de la Iglesia, sus instituciones y sus personas en las comunidades castellanas mediatizaron extraordinariamente el poder local, particularmente a lo largo de la intensa campaña recristianizadora que la Iglesia emprende durante la Restauración. La capacidad legitimadora del poder que emana de las conciencias personales de los creyentes, o de las instituciones y autoridades religiosas es mucho mayor de lo que sospechamos, muy frecuentemente de forma encubierta e indirecta. Hay mucho de religioso por explorar en el poder local, al menos en el que nosotros mejor conocemos, el castellano.

También perviven durante la Restauración buena parte de los hábitos del pueblo decimonónico. Estos comportamientos propios de lo que A.Bahamon$\mathrm{de}^{29}$ ha llamado el "pueblo, como categoría colectiva del siglo XIX" y su concepto de participación política comunal alejado del planteamiento individual y electoral, debieron ser muy importantes en la construcción del poder local en Castilla. El impacto de la cultura anarquista en un segundo momento debió sin duda influir en los hábitos no participativos y en el cambio de la autoridad tradicional. Los efectos del movimiento sindical en la cultura política tampoco han sido suficientemente estudiados desde esta perspectiva específicamente política, tanto desde el punto de vista del conflicto como desde el punto de vista de las nuevas teorías de la participación que defienden. El efecto restaurador que pudo tener el movimiento sindical católico, sobre todo agrario, en la vieja legitimidad y en la autoridad y el orden está sólo intuido. Además de esta orientación, la tensión fundamental entre la participación política socialista y el apoliticismo anarquista debieron estimular el replanteamiento de las posturas populares ante la cosa pública.

La evolución, pues, de las legitimaciones del poder local es una tarea de reconstrucción urgente para los historiadores. Debieron tener un peso intenso las razones de liderazgo y prestigio, muchas veces basadas en la tradición, otras veces modificadas por las sagas, patrimonios, comportamientos y cargos que los antecesores habían ejercido en el ámbito local. Falta por conocer con detenimiento cuándo dejaron de valorarse las tazones personales, familiares y tradicionales y en qué medida, momento y con qué medios comenzaron a actuar componentes ideológicos en la legitimación del poder. Cómo evolucionaron las fidelidades primatias de la familia, la amistad, el personalismo o la vecindad por encima de las redes clientelares o

29 A. BAIAMONDE - J. MArTínez, Historia de España Siglo XIX. Madrid, 1994, capitulo 22 pp. $471-487$.

Heqpania, LIX/1, núm. 201 (1999) 9-36 
los favores concretos. Seguramente que la mayoria de las situaciones fueton mixtas, y en este sentido convendría saber en qué proporción la eficacia de la gestión se superponía a los clichés ideológicos o partidistas, o hasta qué punto etan más importantes las fidelidades personales o familiares por encima de la comprensión de modelos de gobierno ideológicamente difetentes, o más allá de programas de partidos políticos entendidos realmente por las comunidades locales como mensajes diversos o enfrentados entre sí.

La mitificación del caciquismo, acuñada no sólo por los regeneracionistas, sino por los movimientos sindicales católicos agrarios y en general por los partidos no dinásticos, pudo tener mucho de interesado. A veces fue utilizado por los disidentes y periféricos para romper las estructuras de poder vigentes y tratat de sustituirlas. Alguien ha concretado esta idea diciendo que a veces el caciquismo era un fantasma que se utilizaba para justificar que donde no mando yo es porque manda un cacique. Cuántas culpas debidas sin duda a la estructura del Estado y su debilidad, a la incapacidad o corrupción de ciertos gobernantes, a los intereses políticos usureros de muchos intermediarios, han sido redimidas lanzándolas sobre el chivo expiatorio del cacique del lugar.

La lejanía mental del campesino con relación al Estado liberal y parlamentario es otra cuestión relacionada con la cultura y la asimilación o resistencia del poder local que convendría desenttañar. Habrá que matizar la tradicional tesis del abismo abierto entre campesinado y liberalismo. Pero es probable que en esta separación fuera grande, sin duda, el efecto que pudo tener el abandono que las fuerzas progresistas y los movimientos sociales de izquierda practicaron sobre el campesinado. Las fuerzas políticas de izquierda centradas en el proletariado industrial y urbano han abandonado en buena medida al campesinado, las fuerzas más conservadotas e integristas se han ocupado más de él, le han ofrecido más soluciones y por ello ha podido pedirle y obtener más de él más respuestas.

Sólo hemos querido avanzar algunos conceptos de poder local que venimos manejando en nuestra investigación y exponer ciertas pautas por donde discurritá nuestro trabajo de búsqueda sobre el poder local en Castilla. Ahora han de ser la disponibilidad de fuentes y el contenido de la documentación las que decidirán en qué medida y en qué dirección verificamos estas hipótesis. 